British Journal of Education, Society \&
Behavioural Science
$18(3): \begin{gathered}1-16,2016, \text { Article no.BJESBS.29358 } \\ \text { ISSN: 2278-0998 }\end{gathered}$
SCIENCEDOMAIN international
WwW.Sciencedomain.org

\title{
Correlation between Parental Involvement and Burnout among Kindergarten Teachers in Israel's Arab Society
}

\author{
Raed Zedan ${ }^{1^{\star}}$ and Janan Faraj Falah ${ }^{1}$ \\ ${ }^{1}$ College of Education in Haifa, Israel.
}

Authors' contributions

This work was carried out in collaboration between both authors. Both authors read and approved the final manuscript.

Article Information

DOI: 10.9734/BJESBS/2016/29358

Editor(s):

(1) Alina Georgeta Mag, Department of Private Law and Educational Science, University of Sibiu, Romania.

Reviewers:

(1) Rodrigo Lorenzi Poluha, State University Maringá, Brazil.

(2) Norsuhaily Binti Abu Bakar, University Sultan Zainal Abidin, Terengganu, Malaysia And School of Education, University of

Leeds, UK.

(3) Sally Blake, Flagler College, USA.

Complete Peer review History: http://www.sciencedomain.org/review-history/16678

Original Research Article

Received $6^{\text {th }}$ September 2016

Accepted $17^{\text {th }}$ October 2016

Published $26^{\text {th }}$ October 2016

\section{ABSTRACT}

This study seeks to describe the degree of the kindergarten parent's involvement, as well as burnout levels among Arab kindergarten teachers, In addition, the present study will examine the impact of parental involvement on the degree of burnout in the sense of the kindergarten teachers.

The study involved 98 kindergarten teachers, sampled randomly from Arab communities in northern Israel, and was a personal and direct request toward them to participate in the study.

This study used "Multi-choice" questionnaires. The questionnaires are structured, anonymous and intended to be self-reporting, in order to measure the level of parental involvement and aspects according to kindergarten teachers' point of view and measuring the level of burnout amongst them. The answers scale built by the Likert scale of 6 levels (1 - never to 6 - always).

It was found that there are significant negative relationship between perception and involvement as a Share dimensional in general to burnout dimension among all the kindergarten teachers, as 
much the parental involvement is seen as sharing the level of exhaustion, lack of fulfillment, and de-personalization is down and the overall level of burnout decreases.

It was found that there are significant strong positive relationships between general perception of parental involvement and the extent of burnout and general burnout among all kindergarten teachers, as much the parental involvement as general increases the exhaustion, non-fulfillment, and de-personalization increasing and also the general burnout levels increases.

It was found that there is a significant positive correlation between seniority teachers and exhaustion, in correlation when the exhaustion increases the seniority level increases as well, also found that there is a significant positive correlation between seniority teachers and the general burnout when the seniority increases the overall level of burnout increases.

It was found that there is a significant positive correlation between level of education and a sense of non-fulfillment among all the teachers, the higher the level of education increases the level of non-fulfillment arises. And also found that there is significant positive correlation between level of education and a general burnout, as the level of education increases the overall level of burnout increases.

Keywords: Parental involvement; sharing and cooperation; conflict; burnout; exhaustion; nonfulfillment; de-personalization; kindergarten teachers; Israel's Arab Society.

\section{INTRODUCTION}

For more than three decades, there were in Israel in general and in Arab society in particular, many educational and social changes, which led to - among other things, to an increase in the desire of the community in general and parents in particular, to take an active part in the design and formulation of the policy in the state education system [1]. Starting in the nineties, there have been attempts to understand the reasons that lead to the involvement of parents [2], and the demand increased to extend the parental involvement and to form modeling of relationship between the parents and school [3].

In the last two decades, the parental involvement has vastly increased in schools and kindergartens as well. Educators came when their rear wind of change is blowing, and in the socio-educational horizon waving necessity flags of community involvement and partnership [4].

Changes in educational policy and reforms implemented in schools, along with increased behavior problems and violence.

Led the chargers and the educational and public leaders to understanding of the necessary to invest in a joint effort between teachers and parents, otherwise the system may crash. However, despite the strengthening of the phenomenon of parental involvement in schools, in the opinion of the experts it is still far from deeply influencing the educational process and School policymaking [5].
In recent years the relationship has strengthen between parents and school - management and teachers, and as a result increased parent involvement and also increased their influence on what is happening at school, sharing parents has become necessary and essential, and it seems that every respected school engraving on his flag the slogan "parents need to share" [6].

One of the most important factors that parents interact, are the teachers. This relationship affects the quality of teachers' work and also affects the social and moral Pan of the teachers work [7]. Jessie [7], also noted that parental involvement may help teachers and support them emotionally, what leads to reduce in professional burnout.

Burnout was presented as a problem develops in mental health scope for the past fifty years [8].

The beginning of the research on burnout, is in the work of [9] and [10], and it gained momentum in the late twentieth century. The burnout defined as physical weariness, emotional and attitudinal [11], and it is the kind of emotional and cognitive experience, in response to stressful situations, and is considered as the main indicator for the individual welfare [12]. Burnout can be the result of personality factors or the result of professional bodies as well as social factors related to the environment and work conditions [13].

This study seeks to describe the degree of the kindergarten parent's involvement, as well as 
burnout levels among Arab kindergarten teachers, In addition, the present study will examine the impact of parental involvement on the degree of burnout in the sense of the kindergarten teachers.

\subsection{Parental Involvement: Definition, Patterns and Types}

The child spends most of his time with his parents and his family, so the family - through the school system is the primary source values and behavior of the child, educational programs, which included the parents brought good results in the long term, rather than plans that were based only on figures educational learning because the child is exposed to the environment enriching life through significant figures throughout the day [14].

Parental involvement is a multidimensional issue, composed of a variety of behaviors, attitudes and expectations. The involvement is dedication of resources from the parent to the child in a particular area, and the total activity in which parents can participate and who may directly or indirectly contribute to their children's education, parental involvement is a motivated factor to the studies [15].

Epstein [16] emphasized the term "partnership" as an expression of parental involvement, and the meaning is to identify their own interests to share responsibility for their children, to work together and create better plans. Parents sharing in the social and educational process at school is designed to realize their democratic right to do so [17].

The decision of parents to be involved influenced in the wider context by the social environment of the parents' lives [18].

As well as professionals actually will share with parents and children important decisions affecting their lives, there will be more chance that they will be allies for the change and improving in the family functioning [19].

The basis for parental Involvement in the education system is based on their right to influence their children's education. This right is in the source of the principles of the democratic regime, and this involvement in the educational process is the realization of the right, and it allows parents to experience the democratic process. The assumption is that parental involvement may improve the quality of education due to the educational system reference to their point of view, and due to the exposure of school to monitoring and supervising of its clients [5].

The first signs of interest in the connection of parents-school also among the legislature, can be found in surveys conducted by the Knesset research and Information Center Committee [20], at the request of Members of the Knesset, in the following issues: parents' rights in matters relating to education and child welfare and the regulation of the parents status in the educational system.

In an era which the school is part of the community, in a competitive market where schools compete for the support of the parents, parental involvement is very important [21]. Without co-parents, not just the education system currently cannot be successful, it is, as noted, also have trouble to function [22].

Glick [22], cites the Eshed - school workshops facilitator for parents according to Adler method: "It is impossible to grade without reference to the hidden partner, the parents, due to their great impact on the child's behavior and his classroom behavior. "There are children that interfere in classroom in order their parents will be invited, others get legitimacy at home to act as they please. A child who knows that his parents do not value the teacher will develop negative behaviors and disrupt the lesson. If there is no cooperation between the teacher and the parent," she emphasizes, "All attempts to reach the child sentenced to failure. Therefore, a normal relationship with a parent should be established and to communicate the message that full cooperation on his part is in favor of his son."

The decision of the Parents Corporation and involvement, affected by the broader context of their social environment [18].

\subsection{Models and Theories of Parental Involvement}

Combining the parents in the educational context is one of the most important contributors to both parents and teachers alike, the contribution to the parents is expressed in terms of knowledge of the world of the child, self-esteem improvement of the child, raising children's achievements and contribution to the teachers, expressed in terms of practical assistance and 
emotional support reduces the intensity of burnout $[23,24]$.

The definition of parental involvement includes a variety of activities on the part of parents: (A) home conversations; (B) guidance and supervision at home; (C) parents contact with school; (D) taking part in parent-teacher meetings [25]. Friedman [26] chose to conceptualize parental involvement according to four levels:

(A) Passive involvement, including activities not initiated by parents (reporting on the progress of their son at school);

(B) Participation in school activities that organized to the parents (such as Mother's Day);

(C) Active involvement in the educational process (discussion and dialogue with management and teaching staff);

(D) Involvement in policy formulation (disciplinary rules and procedures).

There is overlap between the conceptualization of Friedman presented above and the aspects defined by Epstein [16], a study conducted among 3700 students, their parents and teachers in several elementary schools in the US, he found that parental involvement is reflected in five aspects:

(A) The parent's fundamental commitment to satisfy basic learning needs;

(B) The level of communication from school to home articulated through a comprehensive and clear information about the school;

(C) Parent involvement in school by assistance to its current activities;

(D) Involvement in learning activities by assistance to the parents through workshops;

(E) Parental involvement in policy making through school committees and parents' committees.

Becker, Nkgooa and Crown [27], studied schools in California, USA, which part of the acceptance of students are written commitment (contracts) of parents to be involved in the various activities of the school. Schools considered themselves entitled to terminate the studies of pupil, whose parents have not fulfilled their share of required involvement.

Due to the importance of the issue, voices seeking already to put the issue of parental involvement in the process of teachers training, for instance, Walker and colleagues [28], say that the teachers training to foster parental involvement should be a key component of all teacher training program. Also there is a need to strengthen the job skills of teachers to motivate them to share the parents as part of routine work.

On the other hand the image of the parents in the eyes of teachers and principals is very important, Amit [29], attributes much influence about the image of principals and teachers on parents about their ability to reach a partnership with parents for the benefit of all parties, he said: If they see their parents as enemy - they will fight them; If they see them as a customer - need to satisfy them; And if they see the parents as an economic resource - to take advantage of them.

\subsection{Parental Involvement, Cooperation or Conflict}

In Continue to the power relations taking place between parents and teachers, and the dimension of cooperation between parents and school, reflected in the principle of equality and the principle of pluralism, with the principle of equality requires centralization and less power in the hands of the parents, on the other hand, the principle of pluralism requires decentralization and reciprocity between parents and the school, necessarily it creates conflicts between these two principles [29].

Cooperation - situations where groups work together to achieve common goals, including distinctive reciprocity, Allocation of responsibilities, ability and desire to contribute to and to enjoy the contribution and the balance between the two sides. Amit [29], is in favor of a partnership and argues that it requires building mutual esteem and respect, allocation of roles and responsibility, keeping the autonomy and consideration of any other party.

Conflict - is a process by which individuals or groups believe that others have taken or will take actions that are inconsistent with their interests, this process begins in just disbelief turning to anger, resentment, and actions that aimed harming the other side.

Theories of conflict will compare the expectations of parents from school and the school's expectations of parents. This comparison reveals a substantial difference [30]. Parental expectations constitute as heart's desire than the 
basis for action, and often expressed as general ideal. As such, only in the event of a serious deviation from the parental consensus the parents taking action in order to strive for a change, which may indicate the eruption of the conflict [31].

In contrary to the expectations of parents, school expectations focused and constant, and constitute an action plan. Contradiction between these two sets of expectations leads to conflict, a struggle between conflicting desires or demands relating to values about status, power and resources, which includes an attempt to neutralize the opponent, hurt him and remove him [32].

However, the conflict is also characterized by interdependence and common interest between the two sides on the dispute that divides them. Conflict theory describes a social arena, where individuals and groups compete and battle each other in order to fulfill their individual wishes, however, the conflict is perceived as a gateway of opportunity for positive change [31]. Pasternak [33], indicates that conflicts give rise to the establishment of social order because they allow mobilizing of dormant desires, setting contrasting attitudes and values and the formation of a new equilibrium.

Key elements of conflict can be: incorrect communication between the parties, tend to see our own perceptions and reflecting objective reality, but the perception of the otheras rods by their ideology and personal factors.

The theory of solidarity and awareness [2], explains the formation of the potential involvement of parents. According to this theory, the tendency of parent's involvement in school in the work of their children being formulated by combining different levels of identification of parents with the school as an educational institution and it is and their awareness to what it is being used. High identification of parents with school means, parents are given positive values that the school provides for their children, and that they support the norms which the school stands for. However low identification of parents with school means that parents do not accept the norms and values that the school seeks to impart to their children's [34].

Awareness - meaning the opposite of indifference - means that parents are interested in what is happening at school and its contribution to education of their children and pay attention to what is happening there. Both these elements create the potential for involvement of parents, potential that can be realized under certain conditions [31].

According to Friedman and Fisher [31], when the parent transmitter desire to be involved in and related to school, can occur in one of two processes:

A. Openness and respect for parents: School reveals an attitude of respect and consideration for the parent and the parent's is guided to how to get involved. The school allows fairway, which leads to a state of "idyllic relations." The practical expression to be active or passive involvement.

B. Blocking and closeness: school blocking the parent and does not meet his expectations. The frustrated parent and the expression for involvement will be one of two ways that typical for frustration: Apathy - lack of involvement, or aggressive "negative" involvement. When on the one hand, parents want to know what is going on at school and want to influence, and on the other hand, the principal and teachers want to keep the school autonomy, then conflict will be created.

\subsection{Burnout}

Burnout is defined as a state of depletion of physical and emotional resources of the individual, it follows overachievers that need to realize unrealistic expectations at work, ambitions that the individual himself or his managers puts, on account of their individual's needs, in other words, it's overloaded on the resources energy of the worker and his emotional and intellectual resources $[9,10]$.

Mental burnout is a phenomenon that exists for a long time, but only in the early seventies attention was directed to research with the publication of the work of the psychoanalyst Freudenberger. [9] studied the burnout phenomenon in voluntary care institutions and followed the emotional problems of clinical psychologists, social workers and psychiatrists, caused by prolonged workload. He assumed that burnout is the result of a high level of commitment of the employee takes on his responsibility, and as a result of the heavy load of cases characterized by ineffective coping with 
the demands of the job. Burnout process is accompanied by a sense of depletion, failure, physical and mental [35].

Pines and Aronson [36] expanded the definition, and as well as a decline in physical and emotional (feeling of helplessness and hopelessness, emotional dryness), included also negative self-image, negative attitudes towards work, towards life and towards other people. They defined the burnout as a sense of physically weariness, emotionally and mentally, and distinguish between burnout, which is the result of pressures characteristic of intense prolonged contact with people, and exhaustion, which is a result of environmental pressures, which do not include human contact [36].

Maslach [37], defined burnout as a loss of people of caring persons who is working with them. She explained the burnout as phenomenon of emotional exhaustion and cynicism, arising as a result of interpersonal withhold. She held that, for people working regularly with other people, longterm pressure may dry out your emotions and lead to burnout. Etzion and colleagues [38], define the burnout as "process of grind of a person's emotional resources, slow and incremental process, as result of dullness and well-undefined pressure that grind us down."

According to the Pines and rural [11] [39], burnout is defined as "a feeling of physical exhaustion, emotional and attitudinal."

According to this burnout definition has three components - physical-exercise exhaustion: lack of energy, exhaustion, weakness and exhaustion. Emotional exhaustion: involves a sense of depression, helplessness, hopelessness, feeling the presence of a trap, tension, irritability and depletion of resources. Attitudinal exhaustion: negative attitudes about oneself, to work and his life, his achievements dissatisfaction, low self-esteem, cynical attitudes towards customers and subject. Under this approach, the focus is on the emotional component in burnout and less on the attitude component.

It can be concluded that burnout is an ongoing reaction to emotional pressure and exhaustion of coping resources of the individual, and occurs as a result of prolonged exposure to pressures at work and in life [40]. Following growing ever more difficult to cope with the pressures of work, the individual is experiencing a gradual burnout of expressions of distress and diverse, such as a drop in productivity, alienation from others and emotional exhaustion [38].

The main dimension in emotional exhaustion burnout is developing, slowly, after a series of unsuccessful attempts to overcome the negative stress [41]. Burnout is not like stress, depression or anxiety characterized as temporary. It develops slowly, and does not disappear even after the disengagement from the original stressors [42].

Psycho-social approach that it main representative is Christina Maslc [43], has defined three components of burnout:

A. Mental and emotional exhaustion: (stress at work). Job stress leads to loss of physical and mental energy as a result of high employee involvement.

B. De-personalization: (Evaluation others). Evaluation others decreases, and develop cynical and negative responses to service recipients. Employee experiencing loss of idealism and non-peace of mind.

C. Non-fulfillment: (a negative self-esteem). Arises from the gap between the efforts and achievements and expressed low productivity and morale [43], Maslach and Jackson, Leiter [44,45] divided the conceptual approaches to defining the burnout to three:

A. Setting burnout by Maslach [43] mentioned above.

B. The burnout process consisting of three consequences:

1) Physical impact of this phenomenon on the person and his feelings;

2) Low self-esteem;

3) Development of negative attitudes towards others [36].

C. To these approaches, he added the dimension of cognitive exhaustion (in addition to the emotional and mental exhaustion), characterized by lack of energy, difficulty in thinking and difficulty in making decisions [40].

Etzion and colleagues [38] also noted that burnout is comprised of three components:

- Physical exhaustion: A feeling of overexploitation and burnout of mental 
resources and lack of energy to deal with the demands of work and other people needs.

- Depersonalization inter-personal dimension: the loss of idealism expressed a sense of cynicism and detachment from others. This dimension is often characterized in dehumanizing; Decrease a sense of personal fulfillment.

- The dimension of self-esteem: a sense of failure at work, lack of capacity and low self-efficacy.

It is important to note that, people differ in the degree of vulnerability to stress and their efficiency coping with it. Therefore, an analysis of the burnout would not be complete unless we consider personal factors and personality. People tend to wear out quickly, are characterized by a high sensitivity, they are more dedicated, idealistic and are more likely to be interested in others as human beings, however they tend anxiously, introverted, reveal Rhapsody and tend to over-identify with others [36].

Aronson and Pines [46] adding, the power of burnout experience, length of experience with it, frequency and results, are differ from person to person. Much of the causes of burnout traced back therefore, in the self-individual, work environment and personal surroundings.

\subsection{Burnout among Kindergarten Teachers}

The work of kindergarten teachers is substantially different from the work of teachers, while teachers working in the school - which is a large complex and hierarchical, where each teacher in charge of a unit set, then the kindergarten teachers serve as responsible and exclusive individual administrative-independent units for all events in it [47]. Because of the special nature of this job, the argument often heard the kindergarten teachers fulfill many functions, In fact function as managers and therefore experiencing a higher intensity of stress and burnout [48].

One recent study of Oshrat [48], whose main goal was to identify the stressors, strength and burnout levels which experimented kindergarten teachers, she found that:

Stress intensity and burnout in kindergarten teachers was moderate. Comparing these results to levels stress and burnout among teachers, indicates that the teachers experienced the intensity of stress and burnout are lower than those of teachers, and this despite the fact that all the kindergarten teachers interviewed for the purpose of the first phase of the study indicated that they think the work of kindergarten teachers involves high stress experience, However, research findings indicate that the difficulty to conduct an independent kindergarten as causing stress rated relatively low, and in fact is among the six statements indicated as extremely slight amount of applied stress.

Also found that highest stressors relate to various aspects directly related with the daily work with children, stress arising from the responsibility for the safety of children, stress arising from working with children with difficulties, while statements were rated as extremely slight were the statements relating to organizational aspects related to coordination and interaction outside such as coping with having a kindergarten next to, coordination with complementary In other words, despite the teacher's work involves a wide range of tasks some of which are time-consuming organizational and other resources, the main stress factors arise due to factors material to their work - work with children and supervision., working daily with the assistant.

In other words, despite the kindergarten teachers work involves a wide range of tasks some of which are time-consuming organizational and other resources, the main stress factors arise due to material factors of their work - work with children and supervision.

In contrast, the statements of the highest burnout scale treat physical and mental feeling of general exhaustion, extortion and emptying only in the last component refers to the lack of power to take care of kindergarten children's. You can understand from here that to work with children is indeed stressing the kindergarten teachers, but it seems that the sense of burnout and depletion are the result of total broader factors rather than work with children, other studies support this finding [49].

Oshrat [48], tested also differences in the intensity of stress and burnout of kindergarten teachers suggesting that kindergarten $s$ with various environmental features: gardens in socio-economic environment well-groomed and disadvantaged, gardens from the different 
sectors - state, state religious, private, large and populated gardens compared to small gardens and nursery kindergartens, pre-kindergartens and kindergartens.

Oshrat [48] found that there is difference in stress and burnout in working with children in kindergarten ages. The stress level was the lowest among the kindergarten teachers that teach nursery kindergarten - children age 3-0, a higher stress level was in kindergarten teachers that teach in pre-kindergartens, children aged 4-3 and kindergartens preschool, ages 6-5. This finding can be attributed to that in nursery kindergarten are the expectations of parents and the supervision of the teachers are very modest, low commitment to achieve, in a prekindergartens, and kindergartens achievements expectations both on behavioral and academic levels are high.

In general, dealing with adult children caught most prestigious in the eyes of kindergarten teachers, and often it is asked to what extent the children's in kindergarten have acquired the necessary skills to function properly at the school?

No significant difference in the level of kindergarten burnout that teach children of different ages. This finding is consistent with the fact that the kindergarten mentioned the statement relating "Emotions that they have no power to take care of preschool children's" as lowest statement in burnout scale. It can be specify, that burnout of kindergarten attributed to the broader aspects of the work rather than occupational difficulties with children.

According to a study by Oshrat [48], found that the level of care of the population which is the kindergarten was also a factor that can explain the intensity of the stress and the burnout of kindergarten, it found that kindergarten teachers teach in disadvantaged kindergarten area experienced stress and burnout at higher volumes than kindergarten that teach in kindergartens in nurtured area.

Parents in kindergarten in nurtured area able to contribute their energy, ability and money to improve conditions in the kindergarten. Improvements accessorized, computing, software, support and assistance of trips celebrations are sufficient to support the kindergarten and relieve their stress levels. Less well-tended area the gardens around more resources are needed, differences between high commitment to the profession and the low level of satisfaction from it is a fertile ground for the development of burnout. The segment which the kindergarten is belongs affects the nature of the activities of the kindergarten teachers [48]. For the teachers in the religious state sector the stress and burnout levels higher than those of kindergarten teachers in the state sector, in the private sector kindergarten teachers have lowest levels of stress and burnout.

Oshrat [48] explains this finding in the differential requirements of the three sectors. Every kindergarten teachers in the private sector, attended mostly young children, they should not meet defined academic level, the supervision of this sector is low, and the kindergarten teachers' salary level is a function of the conditions of the garden, and area and prestige of the garden. The kindergarten teachers in the religious state are facing the need to be sufficient to teach both content and skills required in the state and the content and skills derived requirements from SRE (State Religious Education.) These requirements are under time stress can explain the higher experience of the kindergarten teachers in the religious state than that of kindergarten teachers in other sectors.

It was found that the duty of participating in continuing education programs and the professional development requirement, is one of the things that stress and burnout [5]. Professional training and development is a requirement and the terms of the reform plan "New Horizon". Participation in continuing education programs have varied contributions on the one hand continuing education programs expose kindergarten teachers to new teaching methods and these pose to her face new challenges. On the other hand, training kindergarten teachers face them to other requirements, to allocating more time and need to make changes on their working method. The study of a Oshrat [48] examined to what extent the difference in the intensity of stress and burn the kindergarten teachers go to progressing training and kindergarten teachers who rarely kindergarten teachers, there are differences at both stress and burnout levels between the two groups, so kindergarten teachers who rarely going to progressive training experiencing high intensity stress and burnout than their kindergarten teachers who had progressive training. 
Oshrat [48] recommends to kindergarten teachers to do courses throughout the professional career not only as a means of introducing these changes but also since it helps to reduce stress levels and burnout in the kindergarten teachers work.

\subsection{Parental Involvement and Burnout among Teachers and Kindergarten Teachers}

Various studies emphasize the importance of cooperation between parents and the school, and show that involvement of parents in their children improves the respect to schoolchildren to school, and the relationship between students and teachers, as well as improving their achievements Friedman [50]. The purpose of developing the relationship between school and community is mainly in order to raise the level of achievement and motivation to learn and develop and educate good citizens [51].

Jesse [7] found that not only that parental involvement contributes to higher academic achievement of the students and helps promotion, it also improves the self-image of teachers. Parental involvement can help teachers and support them emotionally, which reduces professional burnout.

Moreover, it was found that parental involvement contributes to the morale of teachers, and helping to improve classroom climate and teachers' efforts to increase educational processes [52].

Encouraging parents to support their children at home and recruiting parents to volunteer and be part of the management of the school are activities that are considered as leading to a higher level of academic results at school. This concept adequate research findings that emphasized the quality of relationships between parents and teachers improving their cooperation to develop the intellectual ability of children's [53]. It also found that when parents are more involved in child education, there is greater satisfaction with the functioning of the educational framework [54].

In the Behavioral level, various studies [55] have shown that parental involvement related to high positively to an increase in the achievements of their children and improve their behavior, and more important its reduce in general the violence of students to each other, to their teachers and to school property.

It is important to note that the lack of motivation for learning on the part of students is a major source that causes a feeling of stress and burnout among teachers, also misconduct on the part of students and the inability of teachers to deal with bad behavior on the part of students and non-maintaining discipline, and inability to establish order, can increase the sense of burnout among teachers $[56,57]$.

Studies have also found that lack of respect for teachers from the public in general and parents in particular and the lack of appraisal for teachers and effort they invest are factors that top level of importance that causes stress in their teaching and a sense of burnout, as well as strained relations between teachers, students and their parents [58].

In Meng and Liu analysis of causes to stress and burnout [57], they defined two major factors, first called "working environment of teachers'" and the other was "relationship of teachers -students and their parents."

Even the study by Grayson and Alvarez [59] found that a lack of public and parents appreciation and misconduct on the part of students are increasing the stress and Burnout, frequently changes, reforms and innovations in the educational system, also bringing stress and burnout among teachers [60].

\subsection{Research Hypotheses}

1 a negative correlation will be found between parental involvement in their children in the kindergarten and burnout among kindergarten teachers.

2 a link will be found between seniority and education and the level of burnout between kindergarten teachers.

\section{THE RESEARCH METHODS}

\subsection{Population and Sample}

The study involved 98 kindergarten teachers, sampled randomly from Arab communities in northern Israel, and was a personal and direct request toward them to participate in the study, 48 kindergarten teachers (49\%) belong to the "new horizon" program and 50 kindergarten teachers $(51 \%)$ do not belong to a "new horizon" the average age of 41.27 years teachers with a 
standard deviation 7.56, average seniority of kindergarten teachers seniority years 16.28 with a standard deviation of 7.75 . 31 senior kindergarten teachers $(33 \%), 39$ kindergarten teachers with B.Ed (42\%), 20 kindergarten teachers have bachelor degree B.A (20.5\%) and 6 master's degrees MA (4.5\%).

\subsection{Research Tools}

This study used "Multi-choice" questionnaires. The questionnaires are structured, anonymous and intended to be self-reporting, in order to measure the level of parental involvement and aspects according to kindergarten teachers' point of view and measuring the level of burnout amongst them. The answers scale built by the Likert scale of 6 levels ( 1 - never to 6 - always).

\subsubsection{Measuring parental involvement questionnaire [23]}

The questionnaire includes 18 statements, the items in this questionnaire were based on the distinction between the two dimensions of parental involvement: involvement as sharing and involvement in conflict.

\subsubsection{Sharing and cooperation}

This dimension consists of six items $(1,2,4,6,8$, 11 ), and is constructed by calculating the weighted average of the teachers answers on these items, the proposed ranges from 1 to 6 , as much it is higher, it indicates that kindergarten teachers perceive the involvement of parents as a Sharing. Examined internal consistency reliability of this dimension using Cronbach's alpha coefficient, and found that $\alpha=0.879$.

\subsubsection{Conflict}

This dimension consists of seven items $(3,5,7$, $9,10,12,13)$, and is constructed by calculating the weighted average of the kindergarten teachers answers on these items, the proposed ranges from 1 to 6 , if it is higher, it indicates that kindergarten teachers perceive parental involvement as a conflict with them. Examined internal consistency reliability of this dimension using Cronbach's alpha coefficient, and found that $\alpha=0.770$.

\subsubsection{Questionnaire to measure burnout [61]}

The questionnaire includes 14 statements comprise three dimensions.

\subsubsection{Exhaustion}

This dimension consists of the five items $(1,2,3$, $4,5)$, this dimension was constructed by calculating the weighted average of the kindergarten teachers answers on these items, the proposed ranges is from 1 to 6 , as much is higher, it indicates that the level of exhaustion among kindergarten teachers is high. Examined internal consistency reliability of this dimension using Cronbach's alpha coefficient, and found that $\alpha=0.845$.

\subsubsection{Non-fulfillment}

This dimension consists of five items $(6,7,8,9$, 10 ), this dimension is built by calculating the weighted average of the kindergarten teachers answers on these items, the proposed ranges from 1 to 6 , as much it is higher, it indicates that kindergarten teachers reported they are having high non-fulfillment. 8-worded statement negatively, so it was made as reversal answers. Internal consistency examined the reliability of this dimension using Cronbach's alpha coefficient, and found that $\alpha=0.739$.

\subsubsection{De-personalization}

This dimension consists of four items $(11,12,13$, 14), this dimension is built by calculating the weighted average of the kindergarten teachers answers on these items, the proposed ranges from 1 to 6 , as much it is higher, it indicates that teachers report having high De-personalization. Examined internal consistency reliability of this dimension using Cronbach's alpha coefficient, and found that $\alpha=0.901$.

In addition, the questionnaire includes questions about the consisting part of a kindergarten teachers' background data, such as age, seniority, education.

\subsection{Testing Hypotheses and Findings}

\subsubsection{First hypothesis}

A negative correlation be found between parental involvement in their kindergarten children and burnout among kindergarten teachers.

To examine the relationship between the extent of burnout and the extent of parental involvement, Pearson correlation tests were performed between the variables among all the 
kindergarten teachers and by belonging to the 'new horizon' program.

It was found that there are significant negative relationship between perception and involvement as a Share dimensional in general to burnout dimension among all the kindergarten teachers, as much the parental involvement is seen as sharing the level of exhaustion, lack of fulfillment, and de-personalization is down and the overall level of burnout decreases.

It was found that there are significant strong positive relationships between general perception of parental involvement and the extent of burnout and general burnout among all kindergarten teachers, as much the parental involvement as general increases the exhaustion, non-fulfillment, and depersonalization increasing and also the general burnout levels increases.

\subsubsection{A second hypothesis}

\subsubsection{A link found between seniority and education and the level of burnout among kindergarten teachers}

In order to examine the relationship between the extent of burnout, seniority and education, Pearson correlation tests were performed between variables among all the teachers and by belonging to the 'new horizon' program.

It was found that there is a significant positive correlation between seniority teachers and exhaustion, in correlation when the exhaustion increases the seniority level increases as well, also found that there is a significant positive correlation between seniority teachers and the general burnout when the seniority increases the overall level of burnout increases.

It was found that there is a significant positive correlation between level of education and a sense of non-fulfillment among all the teachers, the higher the level of education increases the level of non-fulfillment arises. And also found that there is significant positive correlation between level of education and a general burnout, as the level of education increases the overall level of burnout increases.

Table 1. Means and standard deviations and burnout extent in involvement among kindergarten teachers in general and by belonging to the 'new horizon' as well

\begin{tabular}{lll}
\hline & \multicolumn{2}{c}{ Total } \\
\cline { 2 - 3 } & \multicolumn{2}{c}{ (N=98) } \\
\cline { 2 - 3 } & Average & S.D. \\
\hline Exhaustion & 2.54 & 1.39 \\
Non-fulfillment & 2.49 & 1.13 \\
De-personalization & 2.01 & 1.03 \\
Burnout & 2.33 & 1.04 \\
Sharing involvement & 4.18 & 0.91 \\
Conflict involvement & 2.52 & 1.2 \\
General involvement & 3.26 & 0.71 \\
\hline
\end{tabular}

\section{DISCUSSION}

Various studies have highlighted the importance of cooperation between parents and the educational institution and teaching staff, studies have also reported on the impact of this relationship between parents and for teachers on different ways of work and educational experience, for the parent and child and the working educational staff if it is principal, teacher or kindergarten teachers.

For example Jessie [7] found that not only is parental involvement contributes to higher academic achievement of the students and helps to prompt them, it also improves the self-image of teachers and may help teachers and support them emotionally, that leads to less professional burnout.

Table 2. Correlations between the extent of burnout and the degree of parental involvement among all kindergarten teachers $(\mathrm{N}=98)$

\begin{tabular}{|c|c|c|c|}
\hline Factor & Sharing involvement & Conflict involvement & $\begin{array}{l}\text { General parental } \\
\text { involvement }\end{array}$ \\
\hline Exhaustion & $-.248\left(^{*}\right)$ & $\left..577^{\star \star \star}\right)$ & $\left..383^{* \star \star}\right)$ \\
\hline Non-fulfillment & $-.270\left(^{*}\right)$ & $.598\left(^{\star \star \star}\right)$ & $\left..3822^{* \star *}\right)$ \\
\hline De-personalization & $-.272\left(^{*}\right)$ & $.601\left(^{* * *}\right)$ & $.397\left(^{\star * \star}\right)$ \\
\hline Total Burnout & $\left.-.2966^{* \star}\right)$ & $.671\left(^{\star * \star}\right)$ & $.440\left(^{* * *}\right)$ \\
\hline
\end{tabular}


Table 3. Correlations between the extent of burnout and the degree of parental involvement among all kindergarten teachers $(\mathrm{N}=98)$

\begin{tabular}{lll}
\hline Factor & Seniority & $\begin{array}{l}\text { Education } \\
\text { level }\end{array}$ \\
\hline Exhaustion & $.296\left(^{\star}\right)$ & 0.183 \\
Non-fulfillment & 0.091 & $.205\left(^{*}\right)$ \\
De-personalization & 0.083 & 0.071 \\
Total Burnout & $.201\left(^{\star}\right)$ & $.217\left(^{\star}\right)$ \\
\hline \multicolumn{3}{l}{$p<0.05$} \\
\end{tabular}

This finding reinforces the findings of my present research, which found that there are clearly negative relations between the concept of involvement as sharing to the dimensions of burnout and general stress among all the kindergarten teachers, as much the parental involvement is seen as sharing the level of Exhaustion, lack of fulfillment, and depersonalization decrease and also the level of the general burnout decreases. And that there are strong positive relationship between the perception of significant involvement as in conflict between burnout and general burnout among all the kindergarten teachers, the more parents involvement seen more as conflict Exhaustion level, non-fulfillment, and depersonalization increase and general burnout levels increase.

And also found that there are significant positive relationship between the perception of general parental involvement to burnout and general burnout among all kindergarten teachers, as much parental involvement as general increases exhaustion level increases, non-fulfillment, and de-personalization and burnout levels are increasing overall.

In the current study, also found that there are strong positive relationship between the perception of involvement as conflict between burnout and general burnout level in kindergarten teachers that do not belong to the 'new horizon', The more the parents involvement perception seen as conflict the exhaustion level, nonfulfillment, and de-personalization and also burnout levels are overall increasing. It was found that there are significant strong positive relationships between general perception of parental involvement and the extent of burnout and general burnout- except for the dimension of non-fulfillment, among kindergarten teachers that not belongs to 'new horizon' program, as much the general of parental involvement increasing the exhaustion level non-fulfillment and general burnout levels increases.

These findings support other studies that reported that parental involvement contributes to the morale of kindergarten teachers, and helping to improve classroom climate and increases the kindergarten teachers' efforts in the educational processes [52].

Encouraging parents to support their children at home and recruiting parents to volunteer and be part of the management of the educational institution are activities that are considered as leading to a higher level of academic results at school. These concept adequate research findings emphasized that the quality of relationships between parents and kindergarten teachers' improves their cooperation in the development of children's intellectual ability [53]. It also found that as much parents are more involved in child education, the satisfaction is greater with the functioning of the educational framework [54]. Mutual satisfaction brings improve in morale and reduces the feeling of stress and burnout.

The closes ties and mutual respect, and evaluating the work of kindergarten teachers' by parents can reduce the feeling of burnout, studies have found, that lack of respect for teachers from the public in general and parents in particular and the lack of respect for teachers for the effort they invest are factors on top level of importance that causing stress in their teaching and enhance the sense of burnout, as well as strained relations between teachers, students and parents $[62,58]$.

A great significance to the involvement of parents on children's behavior, various studies [55] demonstrated that high parental involvement reduces the level of violence of children toward each other and toward the kindergarten teachers and the garden property in general, And this may substantially reduce the feeling of burnout among teachers.

In Meng and Liu analysis [57] for stress and burnout causes, they have defined two main factors, the first called "working environment of teachers" and the other was "teacher's relationships - students and their parents." also in Grayson's and Albers research [59], found that a lack of public and parents appraissation and misconduct on the part of students are increasing the stress and burnout. The findings also showed 
a significant positive correlation between seniority of kindergarten teachers and Exhaustion, as much the seniority is greater the exhaustion in general increases, also it was found that there is a significant positive correlation between kindergarten teachers seniority and the general burnout, as much seniority increases the overall level of burnout increases. And also found that there is significant positive correlation between level of education and a general burnout, as the level of education increases the overall level of burnout increases.

Many researchers have reported a negative correlation between burnout and seniority, it was found out that teachers with less years of experience, especially those who have less than five years of experience, have shown a high level of burnout, particularly in the emotional exhaustion dimension [63].

Also found that young teachers show a high level of burnout, particularly emotional exhaustion and disengagement from the profession due to the lack of experience they have in their relationship with students, parents, supervisors and colleagues [57]. Even Maslach and colleagues [64] found that burnout levels among young teachers are higher than among adults and veteran teachers.

It can be found further support in Gavish and Friedman research findings [65], which indicate that teachers begin their teaching career when they are exhausted and luck of vigor and vitality, distant and alienated from their students and especially hold low professional self-perception.

Even before they got to know well their professional world. Teachers feel bad feelings of professional failure and undermining the sense of capability of their profession. The serious consequence of burnout experience on the teacher, the student and the school has already come into play at the beginning of their career.

Other studies have reported a positive relationship between burnout and seniority when burnout defined in response to ongoing emotional stresses over the time - especially for veteran's teacher, and depletion of coping resources of the individual, that occurs as a result of prolonged exposure to stresses at work and in life [40].

And following ever more growing difficult to cope with the stress of work, The individual is experiencing a gradual expressions of distress and burnout, such as a drop in productivity, alienation from others and de - personalization and emotional exhaustion [38].

About the relationship between the educational level and burnout, current research findings indicate that there is a significant positive correlation between education level and depersonalization dimension, as the level of education increases the dimension of depersonalization will also increase. Also found that there was a significant positive correlation between level of education and a general burnout, as the level of education increases the general level of burnout increases.

Other studies have reported on such a positive relationship between level of education and degree of burnout, Friedman [30] for example, found that as much the level of education is higher the sense of burnout increases. Other studies [46] found that teachers with higher education feel that they have no opportunities to progress and cannot fulfill themselves in accordance with the education they acquired, in addition to inadequate compensation to their talents and qualifications, as expressed in their education.

\section{CONCLUSION}

The conclusions of this study highlight the importance of the relationship between the community in general and parents in particular and the factors involved in the process of education and teaching, This relationship should be partnering and taking part in the educational context, complementing what parents do at home. Parents are an important and major educational practice, their contribution is important and more significant when sharing facts and understanding with the teachers and school staff.

Parental involvement should be coordinated with kindergartens. Which could lead to motivation and satisfaction among kindergartens and don't exhaust them and bring burnout among them.

\section{COMPETING INTERESTS}

Authors have declared that no competing interests exist.

\section{REFERENCES}

1. Friedman J, Fisher J. Parents and school: Attitudes and level of involvement. 
Jerusalem: Henrietta Szold; 2003. [Hebrew]

2. Friedman J, Fisher J. Identification and awakens: Basics parental involvement in school work. Studies in Educational Administration and Evaluation. 2002;26:734. [Hebrew]

3. Toren-Kaplan N. Parents, students and student counselor. Intra Fund for Professional Advancement. 2007;38. [Hebrew]

4. Zahalka A. "The traditional openness" interior. Journal of Culture, Society and Education. 2007;38:45-42. [Hebrew]

5. Zedan R. Teacher job stress, causes and results. Eye Contact "Kesher Ayen" - Irihon Teachers Association Post-primary Schools and Colleges. 2011;209:38-44. [Hebrew]

6. Uziel K. Parents, teachers and everything in between, parents and teachers attitudes towards parental authority, parental involvement and the image of these parents and teachers in these eyes. Working for "Master" Thesis, Social Sciences, Tel Aviv University; 2001. [Hebrew]

7. Jesse D. Increasing parental involvement: A key to student achievement; 2001. Available:http://www.mcrel.org/products/no teworthy/danj.asp

8. Aluja A, Blanch A, Garcia LF. Dimensionality of the Maslach burnout inventory in school teachers. European Journal of Psychological Assessment. 2005;21(1):67-76.

9. Freudenberger HJ. Staff burnout. Journal of Social Issues. 1974;30:159-165.

10. Maslach C. Burned-out. Human Behavior. 1976;5(9):16-22.

11. Pines A, Kafry D. Occupational tedium in the social services. Social Work. 1978;23:499-507.

12. Andrew LL, Bessie PS, Selwyne WC, Stanley KK. An exploration of the burnout situation on teachers in two schools in Macau. Social Indicators Research. 2010;95(3):489-502.

13. Boudrias JS, Desrumaux $P$, Gaudreau $P$, Nelson K, Brunet L, Savoie A. Modeling the experience of psychological health at work: The role of personal resources, social-organizational resources, and job demands. International Journal of Stress Management. 2012;18(4):372-395.

14. Parker DC, Grenville H, Flessa J. Case studies of school community and climate:
Success narratives of schools in challenging circumstances. School Community Journal. 2011;21(2):129-150.

15. Mutch C, Collins S. Partners in learning: Schools' engagement with parents, families, and communities in New Zealand. School Community Journal. 2012;22(1): 167-187.

16. Epstein JL. Perspectives and previews on research and policy for school, family and community partnership. In A. Booth \& J. F. Dunn (Eds.), Family school links: How do they effect educational outcomes? Mahwah, NJ: Lawrence Erlbaum Associates. 1996;209-246.

17. Organisation for Economic Co-Operation and Development. Parents as partner in schooling. Paris: OECD Center for Educational Research and Innovation; 1997.

18. Jessor R. Successful adolescent development among youth in high risk setting. American Psychology. 1995;48: 117-126.

19. Slonim-Nevo F, Lander J. Is the child's best interest can exist separately from the good of the family? Thoughts and recommendations for change. Social and Welfare. 2004;24(4):401-433. [Hebrew]

20. Knesset -Research and Information Center. Regulating the status of parents in the education system compares review. Jerusalem: Knesset; 2004. [Hebrew]

21. Wherry $\mathrm{JH}$. Planning ahead for parent involvement. Principle. 2002;81(5):53.

22. Glick R. Teachers-parents, the involvement of the intervention. Free lesson "Sheor Hofshi", 78 Cheshvan; 2007. [Hebrew]

23. Peled D. The connection between ethical climate and the trust and involvement of parents in school. Final work for the "Master" Thesis, the Department of Education, University of Haifa; 1999. [Hebrew]

24. Henderson AT, Mapp KL, Johnson VR, Davies D. Beyond the bake sale: The essential guide to family-school partnerships. New York, NY: The New Press; 2007.

25. Hu Sui Chu E, Douglas WJ. Effects of parental involvement on eighth grade achievement. Sociology of Education. 1996;69:126-141.

26. Friedman J. Parental involvement in the education process. Monthly Review. 1989;36:34-40. 
27. Becker HJ, Nakagawa K, Corwin RG. Parent involvement contracts in California's charter schools: Strategy for educational improvement or method of exclusion. Teacher College Record. 1997;98:511536.

28. Walker JMT, Wilkins AS, Dallaire JP, Sandler HM, Hoover-Dempsey KV. The Family-School Partnership Lab; 2004.

Available:http//www.vanderbilt.edu/Peabod $\mathrm{y} /$ family-school

29. Amit H. Parents leaders - be an impact parent. Ben Shemen: Modan; 2006. [Hebrew]

30. Friedman J, Bandes Jacob A. Conflict and parents crisis against the education establishment. Jerusalem: Henrietta Szold; 1990. [Hebrew]

31. Friedman J, Fisher J. Parents and school: Interaction and involvement. Papers "Dapim". 2009;47:11-37. [Hebrew]

32. Johnson DE. Faith, hope, tolerance, and sense of community. School Community Journal. 2011;21(1):151-169.

33. Pasternak R. Chapters in sociology of education. Vol B, Tel Aviv, Ramat Aviv: Open University; 2002. [Hebrew]

34. Deslandes R, Rousseau N. Congruence between teachers' and parents' role construction and expectations about their involvement in homework. International Journal about Parents in Education. 2007;1:108-116.

35. Freudenberger HJ, Richelson G. Burnout: The high cost of high achievement. Garden City, NY: Doubleday; 1980.

36. Pines A, Aronson E. Burnout: From tedium to personal growth. New York: Free Press; 1981.

37. Maslach C. A multidimensional theory of burnout. In C.L. Cooper (Ed.), Theories of organizational stress (68-85). Manchester: Oxford University Press; 1998.

38. Etzion D, Tubal $P$, Brknstt $H$. The relationship between psychological measures, physiological, and behavioral in stressful situations. Research Report no. 10/2006. Tel Aviv: Business Research Institute Henry Crown; 2006.

Available:http://y2007.recanati.tau.ac.il/En g/ Uploads/dbsAttachedFiles/WP 102006 Etzion.pdf [Hebrew]

39. Pines A, Kafry D. The experience of tedium in three generation of professional women. Sex Roles. 1981;7(2):117-134.

40. Shirom A. Burnout of teachers in the education system: A literature review and a proposal for dealing system. Studies in Administration and Organization of Education. 1997;21:61-102. [Hebrew]

41. Friedman J, Lotan A. "The world of the teacher" as a predictor of mental burnout. Trends "Magamot". 1987;4:417-434. [Hebrew]

42. Melamed S, Shirom A, Toker S, Shapira I. Burnout and risk of type 2 diabetes: A prospective study of apparently healthy employed persons. Psychosomatic Medicine. 2006;68:863-869.

43. Maslach C. Burnout: A social psychological analysis. In J.W. Jones (Ed.), The burnout syndrome, (68-88). Park Ridge II.: London House Press; 1981.

44. Maslach C, Jackson SE, Leiter MP. Maslach burnout inventory: Manual (3nd). Palo Alto, CA: Consulting Psychologists Press; 1996.

45. Shemesh J. Parents and kindergarten teachers against the reform "New Horizon": kindergarten teachers are exploited and children are hungry; 2012.

Available:http://www.mako.co.il/homefamily-kids/education/Article1ed70b15b989731006.htm Inexhaustible on 29.05.2012 [Hebrew]

46. Aronson E, Pines A. Burnout: From tedium to personal growth. N.Y.: The Free Press; 1981.

47. Ram C. Kindergarten, in: Kashti, s. Arieli, from. And Shlasky, S. Lexicon of education and teaching. Tel Aviv: Ramot. 1997;90. [Hebrew]

48. Oshrat Z. Stress and burnout in kindergarten teachers, lecture at the conference: Opening gates in teacher education. Moffet Institute, Tel Aviv; 2001. [Hebrew]

49. Laugaa D, Rascle N, Bruchon-Schweitzer M. Stress and burnout among French elementary school teachers: A transactional approach. European Review of Applied Psychology. 2008;58(4):241251.

50. Friedman J. School parents relations in Israel, background Initiative; 2010.

Available:Http://education.academy.ac.il.w ork [Hebrew]

51. Kyle DW. Families' goals, school involvement, and children's academic achievement: A follow-up study thirteen years later. School Community Journal. $2011 ; 21(2): 9-24$.

52. Wagner K. Parent involvement (research paper); 2002. 
Available:http://tiger.towson.towson.edu/us ers/kwagne7/researchpaper.htm

53. Epstein JL, Dauber SL. School programs and teacher practices of parent involvement in inner city elementary and middle school. The Elementary School Journal. 1991;91(3):289-305.

54. Chen N. Community school vs. noncommunity school - parents involvement, parental expectations and parental satisfaction with school. "Master" Thesis, School of Education, Bar Ilan University; 1997. [Hebrew]

55. Barton PE, Coley RJ. The family: America's smallest school. Princeton, NJ: Educational Testing Services; 2007.

56. Brundage GC. EFL foreign teacher stress in Korea: Causes and coping mechanisms: A survey study and brief literature review. ERIC Document Reproduction Service ED502354; 2007.

57. Meng L, Liu S. Mathematics teacher stress in Chinese secondary schools. Journal of Educational Enquiry. 2008;8(1):73-96.

58. Lewis R, Romi SH, Qui K, Katz YJ. Teachers' classroom discipline and student misbehavior in Australia, China and Israel. Teaching and Teacher Education. 2005;21(6):729-741.
59. Grayson JL, Alvarez HK. School climate factors relating to teacher burnout: A mediator model. Teaching and Teacher Education. 2008;24(5):1349-1363.

60. Yang X, Ge C, Hu B, Chi T, Wang L. Relationship between quality of life and occupational stress among teachers. Public Health. 2009;123(11):750-755.

61. Friedman J. Burnout of teacher: Concept and measurement. Jerusalem: Henrietta Szold; 1999. [Hebrew]

62. Kyriacou C, Chien PY. Teacher stress in Taiwanese primary schools. Journal of Educational Enquiry. 2004;5(2):86-104.

63. MO KW. Teacher burnout: Relations with stress, personality, and social support. CUHK Education Journal. 1991;19(1):3-11.

64. Maslach C, Jackson SE, Leiter MP. Maslach burnout inventory: Manual (3nd). Palo Alto, CA: Consulting Psychologists Press; 1996.

65. Gavish B, Friedman Y. The teacher as organizations person: The contribution of the environment perceived by the teacher at the beginning of and the end of the first teaching as predicting burnout. Administration and Organization Studies in Education. 2007;29:55-87. [Hebrew]

(C) 2016 Zedan and Falah; This is an Open Access article distributed under the terms of the Creative Commons Attribution License (http://creativecommons.org/licenses/by/4.0), which permits unrestricted use, distribution, and reproduction in any medium, provided the original work is properly cited.

Peer-review history:

The peer review history for this paper can be accessed here: http://sciencedomain.org/review-history/16678 